\title{
Sien (en hoor!) is glo: 'n voorlopige verkenning van ikonisi- teit as retoriese strategie aan die hand van twee kort gedigte
}

\begin{abstract}
Rhetorical text description is aimed at exposing the persuasive strategies employed in a text. It entails a description of the selection of topic, but in particular a stylistic analysis. In this article the researcher explores the necessity of interpreting iconic signification in poetry as a rhetorical strategy, mainly on the grounds of the 'poetic faith' aroused in the reader by the code-orientated or demonstrative nature of poetry. The icon, the most 'seductive' of sign types on account of its rescmblant relation to the denotated object, is seen to function as a 'hidden persuader' in poetic communication, valorizing the message of the poetic utterance. After analysing two short Afrikaans poems (Ernst van Heerden's "Voëlverskrikker" and T.T. Cloete's "God die digter") within this theoretical framework, the researcher concludes that iconicity, at the core of the poetic function in its aspiration towards minimizing the arbitrariness of signification, must be secn as a rhetorical stratcgy.
\end{abstract}

\section{Teoretiese begronding}

Retoriese teksbeskrywing het ten doel om die oorredende strategieë en tegnieke (dit wil sê die kunsgrepe in die teks) wat deur 'n spreker/outeur aangewend word om die opinie en/of gedrag van sy publiek te beïnvloed, te vind en te beskryf. Anders gestel: om die teksstrategieë bloot te lê waardeur 'n stuk inligting, 'n boodskap, 'n tema so 'gevaloriseer' is dat dit 'effektief' word (Wierenga, 1978:161). In terme van die taalhandelingsteorie behels dit 'n beskrywing van die bedoelde perlokusie van uitings (Van Jaarsveld, 1987:4), van die sogenaamde intensie van die abstrakte outeur (Van Coller \& Van Jaarsveld, 1984). Dit verg in die eerste plek 'n analise van die topikale seleksie, maar in die besonder ook 'n stilistiese analise.

Wat poëtiese tekste betref, beklemtoon die retorici dat dit juis die 'selfgesentreerdheid', die kode-georiënteerdheid daarvan is wat dikwels die retoriese situasie bepaal: dit is hoofsaaklik 'demonstratiewe redevoering' waar die 'deviasiebeginsel' (Wierenga, 1978:161), die spesifiek literêre gestruktureerdheid daarvan, die lesersrespons rig. Hier steun dié benadering duidelik op konsepte wat deur die Russiese Formalisme en die Praagse Strukturalisme ontwikkel is. (Dink maar aan die opvattings in formalistiese geledere in verband met 'vreemdmaking' in die letterkunde, aan Jakobson se idee van die 'poëtiese funksie' en aan Mukarovski se begrip 'vooropstelling' - soos onder meer bespreek deur Van Luxemburg et al., 1988:24-27, en Tambling, 1988:24-29.) Dit is konsepte waarteen veral in die afgelope twee dekades heelwat kritiek uitgespreek is, byvoorbeeld deur Fish wat uitwys dat daar nie eintlik iets soos 'normale' taalgebruik bestaan waarvan 'poëtiese' taalgebruik dan 'n afwyking is nie, of deur Derrida wat bevind het dat, op grond van die meerduidigheid en onbeslisbaarheid (undecidability) van tekste, alle tekste effektief 
'literêr' is (Tambling, 1988:39-40,76). Tamblıng (1988:84) vat die kern van hierdie kritiek soos volg saam:

... there can be no marker that distinguishes between forms of utterance, literary or otherwise: all texts embody rhetorical strategies, and literary divices are enshrined within the whole way in which language works through the speaker.

Dat alle tekssoorte retoriese strategieë en literêre tegnieke (kan) benut, val natuurlik nie te betwyfel nie. Hierop het iemand soos Jakobson reeds gewys toe hy ses funksies in elke taaluiting onderskei het ('n emotiewe, 'n konatiewe, 'n referensiële, 'n poëtiese, 'n fatiese en 'n metalinguale), maar beklemtoon het dat een (of meer) sodanige funksie(s) in 'n bepaalde taalgebruiksituasie sal domineer. (Vergelyk Tambling, 1988:37.) Waar die verbale gestruktureerdheid van die boodskap opval of beklemtoon word, waar die uiting se aard as taaluiting benadruk word, sal die poëtiese funksie hiervolgens byvoorbeeld oorheers.

Die Groupe Mu (Wierenga, 197ó.157-15ô) nıeen in hierdie verband dat dit juis die 'interesse' en 'genoeë' is wat deur die kunstige taalgebruik (beelding, stilering, genrekenmerke) opgewek word, wat die leser vir die poëtiese teks en sy boodskap 'sensibiliseer' (sensitief maak). Dit werk uiteindelik 'valoriserend', dit wil sê dit laat dit wat in en deur die teks beweer of geïnsinueer word, waar-skynliker voorkom. Levin (1976:152-153), skrywende vanuit die taalhandelingsperspektief, wys daarop dat dit juis die bykomende dimensie van poëtiese konvensies (metrum, rym, assonansie, ens.) is wat aansienlik bydra om wat hy noem poetic faith by die leser te wek wanneer laasgenoemde 'n poësieteks onder oë kry. Omdat die leser begryp dat hy hier met "locutions with an added dimension" te doen het, is hy bereid tot ' $n$ "willing suspension of disbelief" (Levin, 1976:153). Hy is met ander woorde bereid om van die waarheidsvoorwaardes van normale taalgebruik af te sien ter wille van die mimetiese illokusionêre krag van literêre taal (Ohmann, 1971, aangehaal deur Cloete, 1984:5). Hierdie opheffing van normale illokusionêre kragte laat die leser fokus op die poëtiese lokusies self en op hulle perlokusionère effekte (Cloete, 1984:5).1 Levin (1976:153) se konklusie in hierdie verband onderstreep die valoriserende effek van wat breedweg die liriese taalhandeling genoem kan word:

If the effect of the poetic conventions is achieved on the reader, then any belief in what is said ought to be implicit and total, since the reader has no grounds for judging beyond those vouchsafed him by the poem ... (T)he reader is invited to conceive a world. The conventions are means by which the invitation is made attractive, perhaps even compelling.

Wanneer Cloete derhalwe beweer dat die literêre werk (altyd) primêr lokusie is, funksionerende op foniese, fatiese én retiese vlak (Cloete, 1984:2-3, 7), beklemtoon hy juis dié kode-georiënteerdheid of demonstratiewe aard van poëtiese taalgebruik. Soos hy dit ook stel: "(O)m literatuur te maak, "is to perform a literary structure" - of: "Die literêre werk is 'n taajperformans" (Cloete, 1984:7-8). ${ }^{2}$

\footnotetext{
1 'Lokusies,' 'illokusies' en 'perlokusies' in Austiniaanse sin verstaan, naamlik onderskeidelik (a) as taaluiting met bepaalde verwysing en referensie, (b) as taalhandeling met 'n bepaalde sprekers- of outeursintensie, en (c) as taalhandeling wat 'n bepaalde effek op die hoorder of leser het (Cloete, 1984: 2-3; Van Jaarsveld, 1987:3).

2 Cloete huldig egter 'n verskraalde siening van die illokusionêre en perlokusionêre krag van literêre kunswerke. Dit is volgens hom slegs 'addisioneel' tot die lokusie van die literêre taalhandelingsproduk, terwyl iemand soos Van Jaarsveld (1987:3) tog uitwys dat die drie handelings gelyktydig uitgevoer word in 'n uiting. Cloete onderskei voorts nie tussen bedoelde en werklike
} 
Kortom: In hierdie lig gesien, is juis die 'afwykende' kwaliteit van poësietekste persuasief, 'n retoriese greep - 'n siening wat onder meer deur Luxemburg et al. (1987:62) gedeel word. Die insig - dat die andersheid of afwykendheid van literêre taalgebruik strategies is - is sekerlik geen nuwe nie, en ook glad nie eksklusief tot die retoriese teksbenadering nie. Wat egter hier van belang is, is die besondere wyse waarop die afwykende aard van die poëtiese teks 'verleidelik' werk (interesse, genoeë!), en sodoende uiteindelik persuasief/oorredend.

Ikonisiteit blyk in hierdie verband 'n besonder toepaslike en vrugbaar-werkende begrip te wees. Van Zoest (1978:106) beskou die ikoon as die verleidelikste' literêre teken, met "een soort direkte overtuigingskracht". Ikone werk volgens hom "meer in het verborgene", is - anders as byvoorbeeld simbole en indekse - eerder hidden persuaders. Die ikoon, wat in 'n relasie van gelykenis tot sy gedenoteerde objek staan, beskou hy nogtans as die mees fundamentele tekensoort, en ikonisiteit as 'n besondere eienskap van die literêre werk (Van Zoest, 1978:104-105). Ook Van Coller en Van Rensburg (1982:216) bring ikonisiteit in verband met die bewusgeënkodeerdheid van die literêre teks as boodskap, met die 'bepaalde resultaat' wat die abstrakte outeur met die strukturering van sy boodskap wens te bereik. Bronzwaer (1990:97), in aansluiting by Lotman (Die Struktur des Künstlerischen Textes, 1973), gaan selfs verder:

\begin{abstract}
Počtisch taalgebruik, acticf of passief, is dat taalgebruik waarin wij streven naar maximale iconiciteit van de boodschap ..., waarbij een complexe vorm pas 'eenvoudig' geïnterpreteerd kan worden als zijn complexiteit als icoon gezien wordt van de afwijking die de inhoud vertoont van wat voor ons als prototypisch geldt.
\end{abstract}

Dit is so omdat "literêre werke amper per definisie wil verlei, betower, meevoer: nie verniet nie is Barthes se jouissance (plesier, genot) 'n sterk seksueel getinte metafoor" (Viljoen, 1986:86).

Verhelderend in hierdie verband, is wat byvoorbeeld Peter Abbs (1989:17) oor die estetiese as 'n "mode of intelligence" of ' $n$ "mode of human response and interpretation" geskryf het. Waar die menslike verstand in sy vermoë tot deduksie konsepsueel te werk gaan (analiserend, abstraherend, kategoriserend), gaan hy in sy vermoë tot estesie eerder persepsueel te werk (sensories én gevoelsmatig; onmiddellik integrerend). Die etimologie van die woord ondersteun dié beskouings in verband met die estetiese. Volgens die Oxford English Dictionary is aesthetic afgelei van 'n Griekse woord wat "through the senses" beteken, en kan dit soos volg gedefinieer word: "... of or pertaining to aestheta, things perceptible by the senses, things material (as opposed to things thinkable or immaterial), also 'perceptive, sharp in the senses'". (Die Verklarende Afrikaanse Woordeboek definieer op sy beurt estesie as die "vermoë tot sensasie en gevoel; gevoeligheid", terwyl H.A.T. die betekenis van die Griekse persoonsnaam aisthetes aangee as "waarnemer" én "begryper"!) Hieruit lei Abbs dan af dat die estetiese die mees basiese modus van menslike respons, asook die mees primordiale modus van menslike intelligensie is.

Lees 'n mens dié beskouings saam met bevindinge dat die deurlopendheid van visuele en ander sensoriese metafore in aldagtaal "argues loudly in favor of the contention that thinking takes place in the realm of the senses" (Arnheim, soos aangehaal deur Danesi, 1990:223), en dat die liggaam 'n sentrale rol in ons kognisie speel (Lakoff, soos aangehaal

perlokusies nie. 
deur Violi, 1990:322), kry die eerste helfte van die titel van hierdie artikel sy volle betekenis. En in die lig hiervan moet ikone, hierdie "gemarkeerde ongrammaticaliteiten" in die teks wat "door onze iconiseringsdrift fusei ( = signifiant het natuurlike gelykenis met signifié - BJO) geïnterpreteerd worden" (Bronzwaer, 1990:99), as merkers van estetiese persuasie gesien word - of in terme van die taalhandelingsteorie: as merkers van bedoelde perlokusie.

'n Verdere opmerking van Bronzwaer (1990:99) in hierdie verband is van groot belang: "De meeste, en de meest betekenisvolle, iconen zijn dus die welke wij niet zozeer in de tekst aantreffen als wel aanbrengen, ontdekken of blootleggen; iconen zijn intentionele interpretatiedoelen." (Sy kursivering.) Dit onderstreep die retoriese waarde of perlokusionère krag van ikone as hidden persuaders, as effekte of strategieë in die teks wat 'verlei', wat die konkretisasie stuur. Van Zoest (1978:113-114) wys dan ook daarop dat die begrip ikonisiteit heuristiese waarde het vir die interpretasie van 'n teks.

Voordat daar oorgegaan word om die hipotese dat ikonisiteit 'n retoriese strategie is aan twee kort tekste te toets, eers vlugtig iets oor ikoonsoorte. Van Zoest (1978:109-111) onderskei breedweg tussen drie soorte: topologiese ikone (deur Pierce images genoem), wat in terme van ruimtelikheid beskryf moet word; diagrammatiese ikone (diagrams in Pierce se terminologie), wat in terme van relasie beskryf moet word; en metaforiese ikone (na Pierce se metaphors), waar die gelykenisrelasie nie tussen teken-objek optree nie, maar tussen twee objekte wat albei deur die teken gedenoteer word. Tipografie of klanknabootsing kan byvoorbeeld as topologiese ikone beskou word, bepaalde woordorde-effekte as diagrammatiese ikone, en sekere struktuureffekte in tekste met 'n metafisiese strekking as metaforiese ikone.

In die tekste wat hierna onder die loep geneem word, tref ons al drie soorte aan.

\section{Die patos om verminking}

\author{
Voëlverskrikker \\ teemuskop \\ robotarms \\ leëblikhart \\ rosyntjietepels \\ druiwekorrelnawel \\ sponsrubbermaag \\ vadoeklieste \\ tabaksakkie \\ houtdye \\ knieê \\ kuite \\ voete
}

Uit: Tyd van Verhuising (1975)

- Ernst van Heerden

In hierdie gedig is dit die sintaksis - of die 'afwesigheid' daarvan - en die tipografie wat ikonies funksioneer. 
Met die 'afwesigheid' van sintaksis, die redusering van die gedig tot 'n opeenstapeling van (konkrete) selfstandige naamwoorde, word 'n besondere effek verkry. In die terminologie wat Grăbe (1985:152-158) byvoorbeeld sou gebruik, moet hier gepraat word van vooropstelling (die effek van andersheid of ongewoonheid van poëtiese sintaksis) en delesie (die weglating van normaalweg verwante elemente uit 'n bepaalde sinskonstruksie). Wat 'vooropgestel' word in hierdie gedig, is die gevoel wat die digter het dat hy, ná die amputasie van sy bene, verontmenslik en gereduseer is tot 'n 'ding' 3 ' $n$ voëlverskrikker, 'n parodie van 'n mens. Hiervan is die delesie en die opstapeling van (hoofsaaklik parodiërende) konkreta - die hele gedig dus - 'n hiperteken, en wel as metaforiese ikoon.

Insiggewend is die weglating van die parodiërende voorbepalers in die laaste drie versreëls. Viljoen (1986:85 - op die voetspoor van Corti, 1978) sal dit as 'n breuk in die homomorfisme van die teks beskryf, waardeur 'n bepaalde organisasiebeginsel - hier die parodiërende aard van die komposita - sterk vooropgestel word. Die morfologiese delesie hier, as 'n steeds skrynender voortsetting van die sintaktiese delesie in die hiperteken, en verder versterk deur die tipografiese wit, intensiveer die patos wat die digter (skynbaar) wil kommunikeer. ${ }^{4}$ Ons het hier te doen met 'n byna letterlike oop plek in die teks, wat die leser 'verlei' om die 'ontbrekende' voorbepalers in te vul:

\section{houtdye \\ (hout-)knie ë \\ (hout-)kuite \\ (hout-)voete.}

Dié soort kollaboratiewe deelname van die leser is 'n markante voorbeeld van hoe die leser die "pleasure of the text" (kan) meemaak, daar waar "the seam ... , the fault, the flaw" in die teks geleë is (Roland Barthes, soos aangehaal deur Viljoen, 1986:85-86). Om hierdie rede moet die metaforiese ikoon alhier - die sintaktiese en morfologiese delesie - as 'n retoriese strategie gesien word, waardeur die patos van die digter om sy fisiese verminking vir die leser waar-skynliker gemaak word. Of in terme van die taalhandelingsteorie: as 'n lokusie met die bedoelde perlokusie om patos by die leser te ontlok.

Bogenoemde interpretasie sou ook die geldigheid van Van Zoest (1978:113-114) se uitlating kon illustreer dat die begrip ikonisiteit heuristiese waarde het vir die interpretasie van 'n teks. Dit is juis die blootlegging van die ikonisiteit van die afwykende struktuur van die "Voëlverskrikker"-teks wat as aanleiding dien om dit te interpreteer as 'n metafoor van die digter se patos om sy eie 'verdingliking'.

Die gedig is egter ook in 'n ander opsig ikonies. Die tipografie van die hele teks lyk naamlik soos 'n menslike of voëlverskrikkergestalte (met 'n kop-en-skouers, 'n groteske maag, 'n been). Ons het hier dus ook te doen met 'n topologiese ikoon, wat die verminking en verdingliking van die spreker dubbel-valoriseer, dubbeld so waar-skynlik maak.

\footnotetext{
${ }^{3}$ Malan (1981:56) skryf in hierdie verband van die klasseem 'ding'.

4 Malan (1981: 56-60) verwys in hierdie verband na die effek van 'beklemtoning deur weglating', terwyl hy in verband met die bundel konkludeer dat "die digter telkens sy meer gebruiklike ironiese, serebrale distansiëring prys(-gee) vir 'n affektiewe betrokkenheid".
} 
Die sentrale retoriese houding van die spreker (vgl. Wierenga, 1978:155 in hierdie verband) kan as tweeslagtig gekarakteriseer word, en is verklaarbaar uit die ironiese ingesteldheid van die spreker: aan die een kant gaan hy parodiërend te werk, maar aan die ander kant wil hy tog intense patos kommunikeer. Aan die een kant neem hy dus 'n 'deliberatiewe retoriese houding' in, wil hy empatie by die leser wek; maar aan die ander kant is sy houding 'judikêr', is hy vanweë die lyding wat hy implisiet moet deurstaan, aanklaer én pleiter ... dalk teenoor God?

\title{
3. God se poèsie in alles
}

\author{
God die digter \\ Chili is deur 'n digter gemaak \\ Neruda \\ daar is meer poësie in die sneeuvlokkie \\ as in die letterkunde en baie meer poësie \\ in die miskruier in die toktokkie \\ in die meteorologie en die entomologie \\ in die moremis en in die bergpiek \\ die horison wat in die hemel wegraak \\ in die rooswolk is daar baie meer liriek \\ die aarde is deur 'n digter gemaak
}

Uit: Driepas (1989) - T.T. Cloete

Van Driepas het die digter gesê dat hy daarmee 'n katedraal wou maak (Krüger, 1990:11). Saamgelees met wat Grové (1990:8) in verband met die implikasies van die bundeltitel gesea het, naamlik dat dit op die drieledigheid van die bundelinhoud slaan ("die rusteloos soekende mens, die wonderbaarlike skepping ... en dan veral God wat sy werke in die kosmos laat sien ..."), word die sterk religieuse inslag van die bundel duidelik - soos trouens geld van die hele Cloete-oeuvre. In terme van hedendaagse literêre teorieë moet dit waarskynlik as 'n duidelike ideologiese stellingname bestempel word.5

Wat Van Luxemburg et al. (1987:61-62) dus skryf oor onder meer "christelijke literatuur" en oor "alle literatuur die een bepaalde boodschap wil uitdragen of vanuit een bepaalde ideologie is geschreven", lyk hier besonder relevant. Hulle beskryf sulke literatuur as persuasiewe tekste wat sterk op die leser gerig is, met "bepaalde procédés om de lezer mee te slepen ..., te ontroeren, te amuseren of te onderrichten". Hoe relevant dié beskouings is,

\footnotetext{
5 Dit wil se indien ideologie in 'n positiewe sin begryp word as ' $n$ "sisteem van idees of waardes wat geld as verwysingsraamwerk vir 'n verstaan en evaluering van die ervaring" (Degenaar, 1985:123), of indien dit in Marxistiese sin verstaan word (Coetzec, 1986:4-6). Goudzwaard (1981:26-28), byvoorbeeld, sal egter nie hiermee akkoord gaan nie, aangesien by wil onderskei tussen die ware (Christelike) religie en 'n idcologie wat hoogstens "een imitatie-religie, ... cen pseudo-openbaring van zin, zonde en heil" kan wees.
} 
blyk byvoorbeeld reeds uit die kritiek wat teen aspekte van Driepas uitgespreek is. Merwe Scholtz (1990:11) meen dat die uitgebreide gebruik van die enumerasietegniek naderhand "'n eenselwigheid, 'n een-tonigheid" in die hand werk; dat die "poëtisering" van wetenskaplike gegewens "op die duur resepperig klink"; en dat die veelvuldige enumerasies die struktuur "as't ware te lineêr ..., te enkel beskrywend en te 'neutraal"' laat word. Grové (1990:8) verwys na gedigte "wat wil-wil vasval in betoog", terwyl Spangenberg (1990:17) skerp krities reageer op wat hy die "styl-oordaad en styl-opsetlikheid (maniërisme)" in die bundel noem.

la van Zyl (1990:5) se reaksie op bogenoemde kritiek is vir die doeleindes van hierdie artikel besonder belangrik, aangesien dit - onder meer - kenmerkende retoriese strategieë in die bundel uitwys (hoewel nie by name nie). Sy wys eerstens op die besondere aard van die (omvattende) estetiese belewing wat in die bundel weerspieël word: "sintuiglikbelewend én metafisies-besinnend". Dit herinner sterk aan die funksies wat volgens die H.A.T. in die oorspronklike Grieks aan die esteet toegeken is (waarnemer én begryper), en laat al dadelik die eerste helfte van die titel van hierdie artikel resoneer.

Van Zyl le in die tweede plek besonder klem op Cloete se "heel besondere eie idiolek". Dit sluit "'n voorliefde vir die buitengewone woord, die meerlettergrepige woord, selfs die neologisme" in, en hang saam met die aard van dié poësie "wat letterlik die verste grense van die skepping wil betrek". Hierby moet volgens haar die tipiese enumerasietegniek gereken word ("the universe fatigues with its infinitude", lui die motto van die gedig op hladsy 176 in die bundel), asook wat sy noem die "rymvermoë", die tipiese woord- en klankspel, die bewustheid "van die paradoksale in die skepping, wat uitloop op die voorliefde vir die paradoks as stylfiguur", en die "byna bedwelmende, barokke woordoordaad" wat dwarsdeur die bundel aangevoel word. In totaliteit herinner die beskrywing van die Cloete-idiolek (veral ten opsigte van die funksies van die herhalingsbeginsel) aan die retoriese funksie van topikale infinitisering, waardeur die konkrete, lokale en unieke 'geamplifiseer' word tot die nie-gepersonaliseerde, nie-getemporaliseerde en niegelokaliseerde (Wierenga, 1978:150).

Laastens meen Van Zyl (1990:5) dat dit belangrik is "om nie die humor in die bundel mis te lees nie ... 'n humor wat eerder 'n ontwikkeling vanuit die ironie as 'n geesverwant van die geestigheid is". Hier dink sy aan die "verbluffende vermoë om vir 190 bladsye lank die rym vol te hou", die assonansies en alliterasies in 'n gedig soos "Land van die eggo's" wat dalk die spot dryf "met hierdie hebbelikheid by die digter self", die bewustheid van die paradoksale in die skepping, die "ontluisterende selfspot", en selfs die 'woordoordaad' wat "op 'n postmodernistiese wyse" miskien wil "kommentaar lewer op die leser se geykte verwagtinge ten opsigte van đie poësie as 'n gekonsentreerde literêre vorm." Wat Van Zyl hier "humor in die bundel" noem, kan dalk presieser omskryf word as vooropstelling van die 'afwykende' kwaliteit van poësietekste, van 'n doelbewuste bewusmaking van die demonstratiewe aard van poëtiese taalgebruik, ${ }^{6}$ wat via die leser se 'interesse' en 'genoeë' hieraan, sensibiliserend en uiteindelik oorredend werk.

Wat vir die bundel geld, geld in hoë mate ook vir die onderhawige gedig. Dit weerspieël op kernagtige wyse die essensie van die estetiese ervaring: dis juis die (geïmpliseerde) sintuiglike waarnemings wat voorwaarde is vir die 'metafisiese besinning' en die slotsom in die gedig ("die aarde is deur 'n digter gemaak"). Die gedig staan voorts geskryf in heelwat

${ }^{6}$ Cloete (1984: 8) self sou praat van die 'outo-illokusie' van die literêre taalhandelingsproduk. 
van die tipiese Cloete-idiolek: natuurwetenskaplike verwysings ("meteorologie" en "entomologie"); enumerasies ("in die sneeuvlokkie ... in die miskruier in die toktokkie ...," ensovoorts); volgehoue (kruis-)rym; klankspel (waaroor later meer); paradokse ("sneeuvlokkie" ensovoorts vs. "letterkunde"; "God die digter" vs. die menslike digter, byvoorbeeld Neruda); "woordoordaad" (die talle konkreta en abstrakta wat die Goddelike digterskap moet bevestig). En laastens: die gedig is baie bewus - en maak die leser baie bewus - van sy demonstratiewe aard, van sy 'digterlikheid'. Die woord digter staan byvoorbeeld in die titel, die motto én in die kernspreukagtige slotreël van die gedig. Die frase wat die meerderwaardigheid van die goddelike digterskap beklemtoon, word tot driemaal toe (met afwykings) herhaal: "daar is meer poësie" (r. 1), "... en baie meer poësie" (r. 2), "... is daar baie meer liriek" (r. 7). Maar die bewustheid en die bewusmaking van die teks se literariteit is ook veel subtieler verdiskonteer, naamlik in die gedig se hegte klankkomposisie en in die deur die enumerasies verkompliseerde sinskonstruksie (twee nogal uitstaande kenmerke van Cloete se poësie oor die algemeen) - wat ons bring by die eintlike fokuspunt van hierdie artikel: ikonisiteit in die gedig.

Cloete (1985:8) het self aangetoon dat klank in 'n gedig, behalwe foniese, semanties uitbreidende en ritmiese funksies, ook 'n organisatoriese funksie het. In die onderhawige gedig word die funksie selfs verder gevoer: dit word die stramien van die gedig, die beginsel waarop die gedig gebou word, ikonies van die boodskap van die teks. Die digter het dit in die gedig naamlik oor die wyse waarop "God die digter" sy poësie in die besonderhede van die skepping openbaar, en boonop veel wonderbaarliker as wat die mens dit in sy "letterkunde" kan (na-)doen. Dit demonstreer Cloete nie deur dié besonderhede van die skepping te probeer beskryf of uit te beeld nie, maar deur telkens sekere van die klanke in die woord poësie direk of in nabye verwantskap te laat resoneer in die woorde waarmee dié skeppingsdinge benoem word. So weerklink die [o], [s] en [i] van "poësie" in die [s], [0] en [i] van "sneeuvlokkie"; die [ə] en [s] word weer in "miskruier" gehoor; "toktokkie" laat die [i] en [o] (lg. in die verwante [j]) resoneer; die [o] en [i] kom in sowel "meteorologie" as "entomologie" voor; ensovoorts, totdat ons laastens die [o] en [s] in die poëtiese "rooswolk" hoor eggo. Opvallend val die woord "letterkunde" (r. 2) byna 'wanklankig' buite hierdie foniese patroon (met uitsondering van die dowwe, neutrale [0]). Die woord "letterkunde" bring met ander woorde 'n breuk in die foniese homomorfisme teweeg - wat juis die hegte klankkomposisie in die teks vooropstel (voorts deur die kruisrym versterk).

In terme van die onderskeide wat Van Zoest ten opsigte van ikoonsoorte getref het, moet die besondere klankkomposisie in die gedig in die eerste plek as diagrammaties ikonies, maar miskien veral as 'n metafories ikonies - metafories van die digterskap van God geïnterpreteer word, terwyl die homomorfiese breuk in "letterkunde" eerder as 'n topologiese ikoon gesien kan word.

Die sintaktiese struktuur van die gedig funksioneer eweneens op verskillende wyses ikonies. Die leestekenlose gedig moet heel waarskynlik as 'n enkele, veelvoudige sin gelees word, veelvuldig uitgebrei deur aaneenskakelende en - en anaforiese in die-konstruksies, voordat daar in die slotreël gekonkludeer word ('n dubbelpunt is aan die einde van die voorlaaste reël te veronderstel). Word die sintaktiese uitgebreidheid in verhouding gesien tot die omvattendheid van die goddelike digterskap, is dit duidelik dat hierdie 'n diagrammatiese ikoon is. Die 'omvattendheid' word verder as't ware sigbaar gemaak, of 
'afgebeeld', deur die inversionele herhaling (met enkele leksikale vervangings of uitbreidings) van die openingsreël in die voorlaaste reël. Die skepping waarin God homself as digter by uitstek openbaar - soos vanaf die tweede helfte van reël 1 tot en met die eerste helfte van die voorlaaste reël opgesom - word op hierdie wyse deur die frase "daar is meer poësie" /"is daar baie meer liriek" omlys. Dít moet as 'n duidelike topologiese ikoon geïnterpreteer word.

Die strewe na maksimale ikonisiteit van die boodskap is die besondere waarmerk van die poëtiese taalgebruik in hierdie gedig, van sy literariteit of outo-illokusionisme (Cloete, 1984:8). En soos reeds voorheen beredeneer, het die direkte oortuigingskrag van die ikoon, die jouissance wat die leser aan die interpretasie van dié soort teken het, 'n valoriserende funksie - in die besonder in dié gedig waar dit oor die uitnemende digterlikheid van die Skepper handel! Dit werk oorredend, het illokusionêre krag, en moet hier beslis as 'n retoriese strategie gesien word.

Die slotreël verklap myns insiens op nog markanter wyse die retoriese aard van dié gedig. Dit is 'n kategoriese, enkelvoudige sin, 'n sinsoort wat volgens Weaver (1986:281-282) weens die bondigheid en strukturele eenvoud daarvan juis geskik is om sinopties en dramaties in diskoerse aangewend te word, veral aan die begin of aan die slot daarvan (soos hier). Op hierdie wyse gebruik, het dit sterk oorredingskrag, veral ook as dit - soos in hierdie gedig - staan teen die agtergrond van die komplekse, veelvoudige konstruksie wat dit voorafgaan. Dié retoriese effek word in "God die digter" boonop versterk deur die amplifiserende kontrastering van die slotreël met die gedigmotto: waar Pablo Neruda van Chili gesê het dat dit deur 'n digter gemaak is, oortuig Cloete die leser dat die hele aarde deur 'n digter gemaak is!

\section{Gevolgtrekking}

Waar Ernst van Heerden in 1953 in sy artikel "Riglyne by die ondersoek van die digterlike beeld" (opgeneem in Van Heerden, 1971:17-32) nog beweer dat die poësie in sy wese 'beeldend' bly, wonder 'n mens in 1991 of dié voorrang nie eerder die verskynsel van ikonisiteit toekom nie. Wat in elk geval duidelik is, is dat die konkretiseringsvryheid wat byvoorbeeld deur die dekonstruktiviste aan die leser toegeken word, oordrewe is. Soos Bronzwaer (1990:93 en 102) dit op die trant van Michael Riffaterre stel: die poëtiese funksie is juis "dát taalgebruik waarin wij aan de willekeur der tekens proberen te ontsnappen". Dit kan essensieel as 'n retoriese funksie gesien word. ${ }^{7}$ In hierdie proses speel ikone, as hidden persuaders, 'n belangrike indien nie sentrale rol nie. Dit het die analise van die twee onderhawige gedigte (hopelik) bewys.

Soos Ernst van Heerden 'n opmerking van J.M. Murray in dieselfde artikel oor die digterlike beeld vertaal het: "... elke blywende literêre werk ... (is) nie soseer 'n triomf van die taal nie, maar 'n oorwinning oor die taal."

\footnotetext{
7 Wierenga (1978:156) wys byvoorbeeld daarop dat die onderskeiding van die demonstratiewe retoriese genre analoog is aan Jakobson se onderskeiding van die poëtiese funksie.
} 


\section{Bibliografie}

Abbs, P. 1989. Tactful approach to life. The Times Higher Education Supplement : 17. Jan., 15. Bronzwaer, W. 1990. Poëzie en iconiciteit. Fonum der Letteren, 31(2):93-103. Junie.

Cloete, T.T. 1984. Taalhandelinge en die literatuur. In: Van Coller, H.P. en Van Jaarsveld, G.J. (reds.): Woarde as dade: Taalhandelinge en letterkunde. Durban : Butterworth. p. 1-14.

Cloete, T.T. 1985. Hoe om 'n gedig te ontleed. Pretoria : Academica. Derde druk.

Cloete, T.T. 1989. Driepas. Kaapstad : Tafelberg-Uitgewers Beperk.

Coetzee, Ampie. 1986. Ideologie, letterkunde, literêre kritiek. In: Botha, E. \& Snyman, N. (reds.) Program en problematiek. Handelinge van die stigtingskongres van die Afrikaanse Letterkundevereniging, 25 en 26 Oktober 1984. ALV-Publikasiereeks 1. Durban : Butterworth. p. 3-10.

Corti, M. 1978. An introduction to literary semiotics. Bogat, M. \& Mandelbaum, A. (Transi.) Bloomington/London : Indiana University Press.

Danesi, M. 1990. Thinking is seeing: Visual metaphors and the nature of abstract thought. Semiotica, 80(3/4):221-237.

Degenaar, J J. 1985. Ideologie, vervteemding en woordkuns. In: Malan, C.; Smit, B. (reds.). Skrywer en gemeenskap. Pretoria : HAUM-Literêr. p. 123-136.

Goudzwaard, B. 1981. Genoodzaakt goed te wezen. Christelijke hoop in een bezeten wereld. Kampen : Kok. Tweede druk.

Gräbe, I. 1986. "Droogte": aspekte van poëtiese taalgebruik - teoretiese uiteensetting en tôpassing. In: Senekal, J.H. (red.): Teks-leser-konteks. Johannesburg : Perskor-Uitgewery. p. 12-43.

Grove, A.P. 1990. Van seksofrenie tot fel erotiek. Driepas 'n ware kragtoer. Beeld : 8, Febr. 5.

Kritzinger, M.S.B.; Labuschagne, FJ.; Pienaar, P. de V. 1972. Verklanende Afrikaanse Woordeboek. Pretoria : Van Schaik Beperk. Sesde uitgawe.

Krüger, E. 1990. Die man het 'n katedraal gebou in 'n jaar. Beeld : 11, Jan. 11.

Levin, S.R. 1976. Concerning what kind of speech act a poem is. In: Van Dijk, T.A. (red.): Pragmatics of language and literature. Amsterdam : North Holland Publishing Company. p. 141-160.

Malan, C. 1981. Van vorm tot vorm - transformasie van die ek in Tyd van verhuising. In: Coetzee, AJ. (red.). Hulsels van kristal. Kaapstad : Tafelberg-Uitgewers. p. 5462.

Odendal, F.F., Schoonees, P.C., Swanepoel, CJ., Du Toit, S.J., Booysen, C.M. 1981. Verklarende Handwoordeboek van die Afrikaanse Taal. Johannesburg: Perskor-Uitgewery. Tweede uitgawe, tweede druk.

Ohmann, R. 1971. Speech acts and the definition of literature. Philosophy and Rhetoric, iv(1):1-19.

(The) Oxford English Dictionary, Second edition, 1989. Volume I.

Scholtz, M. 1990. Verskeidenheid, maar ook eenselwigheid. Die Burger : 11, April 5.

Spangenberg, D.F. 1990. T.T. Cloete: poësic as étalage. Van pyn tot pret ... Rappon : 17, Maart 4.

Tambling, J. 1988. What is literary language? Milton Keynes, Philadelphia : Open University Press.

Van Coller, H.P. \& Van Jaarsveld, GJ. (reds.) 1984. Inleiding tot: Woorde as dade: Taalhandelinge en letterkande. Durban : Butterworth.

Van Coller, H.P. \& Van Rensburg, M.CJ. 1982. Van mond tot oor. In: Van Jaarsveld, GJ. (red.): Wat $s \boldsymbol{d} j$ ? Studies oor taolhandelinge in Afrikaans. Isando : McGraw-Hill Boekmaatskappy. p. 211233.

Van Heerden, E. 1971. Rekenskap. Letterkundige opstelle. Kaapstad : Tafelberg-Uitgewers Beperk. Tweede druk.

Van Heerden E. 1971. Riglyne by die ondersoek van die digterlike beeld. In: Van Heerden, E. Rekenskap. Letterkundige opstelle. Kaapstad : Tafelberg. p. 17-32.

Van Heerden, E. 1975. Tyd van verhuising. Kaapstad : Tafelberg-Uitgewers Beperk. Tweede druk.

Van Jaarsveld, G.J. (red.) 1987. Inleiding: Wat doen jy met woorde? In: Wat bedoel jy? Pretoria : Serva-Uitgewers. p. 1-13.

Van Luxemburg, J., Bal, M., Weststeijn, W. 1987. Over literatuur. Muiderberg : Dick Coutinho.

Van Luxemburg, J., Bal, M., Weststeijn, W. 1988. Inleiding in de literatuwnetenschap. Sesde druk. Muiderberg : Dick Coutinho.

Van Zoest, A.JA. 1978. Peirciaanse semiotiek. In: Grivel, C. (red.): Methoden in de literatuunwetenschap. Muiderberg : Dick Coutinho. p. 102-114. 
Van ZyL, I. 1990. T.T. dig slim oor skepping. Die Republikein : 5, Jun. 29.

Viljoen, H. 1986. "Die klou dui al dic dier aan": cor semiotiek en literatuur. In: Senekal, J.H. (red.): Teks-leser-konteks. Johannesburg : Perskor-Uitgewery. p. 81-98.

Violi, P. 1990. Body, experience and meaningful things. Semiotica, 80(3/4):321-336.

Weaver, R.M. 1986. Some rhetorical aspects of grammatical categories. In: Brock, B.L. \& Scott, R.L. (reds.): Methods of metorical criticism. A twentieth century perspective. Detroit : Wayne State University Press. Tweede uitgawe, derde druk. p. 273-295.

Wierenga, L. 1978. Rhetorische tekstbeschrijving. In: Grivel, C. (red.): Methoden in de Literanurwetenschap. Muiderberg : Dick Coutinho. p. 149-165.

Universiteit van die Oranje-Vrystaat 
